\title{
Analisis Pekerjaan Pondasi Bored Pile, Pile Cap Serta Secant Pile Berbasis AHP (Analytic Hierarchy Process) Pada Proyek Bangunan Basement 5 Lapis
}

\author{
Divy Wira Agusma ${ }^{1}$, Albert Eddy Husin ${ }^{1, *}$ \\ Program Studi Magister Teknik Sipil, Universitas Mercu Buana, DKI Jakarta ${ }^{1}$ \\ Koresponden*,Email: albert_eddy@mercubuana.ac.id
}

\begin{tabular}{lll}
\hline & Info Artikel & Abstract \\
\hline Diajukan & $25 \mathrm{Mei} 2021$ & Especially for the DKI Jakarta province, basement is a substructure work that is very much \\
Diperbaiki & 21 Juli 2021 & needed in high-rise residences due to the limited land available, during the basement \\
Disetujui & construction process, especially basement 5 work, rework and delays may occur. Many factors \\
& affect the occurrence of rework and delays in the work of boring pile foundations, secant piles \\
& and pile caps for the 5-layer basement project, the AHP (Analytic Hierarchy Process) \\
& simulation method using expert choice software can determine the factors that affect the work \\
& rework and delays in foundation work for boring piles, secant piles and pile caps for the 5-layer \\
& basement project. This research methodology consists of 3 stages including literature study and \\
& initial survey, the second stage is collecting data, then the third stage is conclusion analysis. \\
& After applying the AHP (Analytic Hierarchy Process) simulation method using expert-chosen \\
& software, it is known that the most dominant factor in influencing the occurrence of work \\
& (rework) and delays in the work of boring pile foundations, secant piles and pile caps for the \\
& 5-layer basement project is the field team design knowledge of 1.20 \%, the non-dominant factor \\
is $1.60 \%$ inspection.
\end{tabular}

Keywords: high rise building, basement,

Kata kunci: gedung bertingkat tinggi, basement, pekerjaan ulang, keterlambatan, metode AHP

\begin{abstract}
Khusus Provinsi DKI Jakarta basement merupakan pekerjaan struktur bawah yang sangat dibutuhkan pada hunian bertingkat tinggi dikarenakan keterbatasan lahan yang tersedia, selama proses konstruksi basement khususnya pekerjaan basement 5 lapis akan berpotensi terjadi pekerjaan ulang (rework) serta keterlambatan. Banyak factor-faktor yang mempengaruhi terjadinya pekerjaan ulang (rework) serta keterlambatan pada pekerjaan pondasi bored pile, pile cap serta secant pile proyek basement 5 lapis, metode simulasi AHP (Analytic Hierarchy Process) menggunakan software expert choice dapat mengetahui faktor - faktor yang mempengaruhi pekerjaan ulang (rework) serta keterlambatan pada pada pekerjaan pondasi bored pile, pile cap serta secant pile proyek basement 5 lapis. Metodologi penelitian ini terdiri dari 3 tahap diantaranya studi pustaka serta survei awal, tahap kedua melakukan pengumpulan data, kemudian tahap ketiga adalah analisis kesimpulan. Setelah mengaplikasikan metode simulasi AHP (Analytic Hierarchy Process) menggunakan software expert choice diketahui Faktor paling dominan dalam mempengaruhi terjadinya pekerjaan ulang $x$ serta keterlambatan pada pekerjaan pondasi bored pile, pile cap serta secant pile proyek basement 5 lapis adalah pengetahuan desain tim lapangan sebesar 12,20 $\%$, faktor yang tidak dominan adalah sistim inspeksi sebesar $1,60 \%$.
\end{abstract}

\section{Pendahuluan}

Melihat berbagai fasilitas yang terdapat pada konsep apartemen, sehingga dapat menciptakan suatu kawasan yang mandiri, nyaman, dan mempunyai privasi tinggi dimana sangat ideal untuk para masyarakat yang tinggal di kota-kota besar seperti Jakarta.

Terkait dengan jumlah perkantoran di area Jakarta Pusat, berdampak terhadap kebutuhan hunian bertingkat tinggi yang terus meningkat pada daerah tersebut, sehingga penelitian berkaitan dengan hunian bertingkat tinggi apartemen untuk menganalisis kinerja biaya serta waktu dengan studi kasus sangat penting dilakukan, dengan harapan dapat berkontribusi terhadap dunia akademisi maupun praktisi.
Stuktur bawah adalah seluruh bagian struktur gedung atau bangunan yang berada di bawah permukaan tanah. Struktur bawah tanah atau basement sering dijumpai pada gedung gedung bertingkat dengan kapasitas yang besar agar dibangunnya basement. Basement berfungsi sebagai lahan parkir, Fasilitas atau kebutuhan item mechanical electrical serta plumbing dan lain - lain. Basement dapat mengurangi kebutuhan lahan. Dengan penilitian penulis yang mengarah ter-hadap pembangunan hunian bertingkat tinggi apartemen yang mencapai 50 lantai maka hal tersebut juga berdampak terhadap kebutuhan ruangan mechanical, electrical, plumbing serta parkir tanpa melanggar peraturan Pemerintah Daerah Ibukota Jakarta. 
Untuk melihat ilustrasi pembangunan Basement 5 lapis dapat dilihat pada Gambar 1 dan 2.

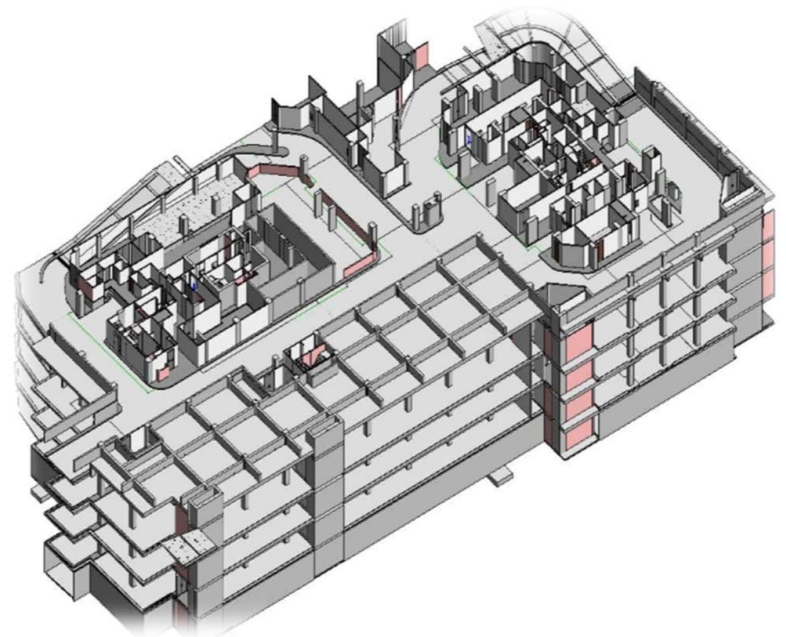

Gambar 1. Gambar 3 Dimensi Pekerjaan Basement 5 Lapis

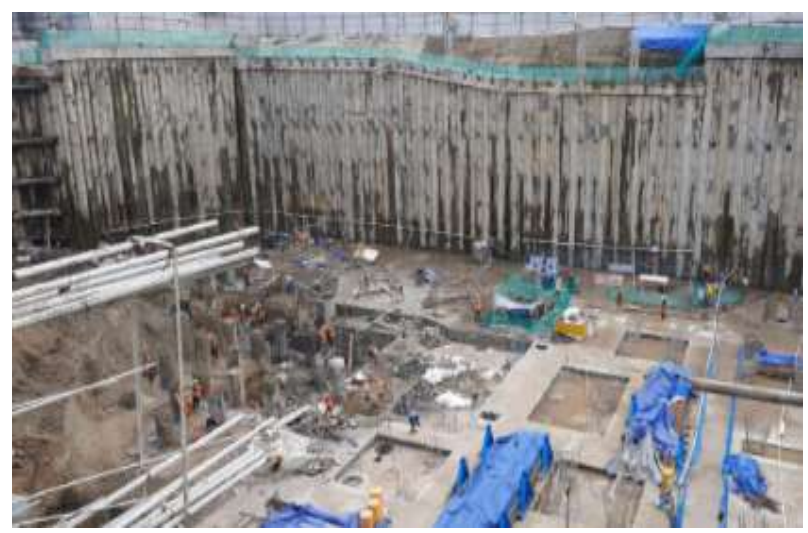

Gambar 2. Dokumentasi Pekerjaan Pondasi Bored Pile, Pile Cap dan Secant Pile Proyek Basement 5 Lapis

Menurut R. W. M. Wong, berikut beberapa hal yang mempengaruhi konstruksi pekerjaan basement dengan kedalaman melebihi 20 Meter [1]:

1. Ukuran proyek

2. Volume Pekerjaan

3. Bentuk dan kondisi topografi

4. Lingkungan dan kondisi proyek

5. Kondisi geoteknik

6. Tata letak internal basement atau item lainnya

7. Ketersedian sumber daya

8. Ketersediaan tenaga ahli

9. Kesesuaian metode yang akan digunakan

10. Persyaratan kinerja khusus yang akan diperlukan
Pada proyek konstruksi yang terbilang besar, biaya pekerjaan ulang (rework) diperkirakan rentang 5\% sampai 20\% dari biaya proyek [2]. Merumuskan cara terbaik untuk mengurangi pekerjaan berulang (rework) perlu dilakukan simulasi terlebih dahulu dalam bentuk mode [3]. Selain menimbulkan biaya tambah, pekerjaan ulang dapat berpotensi menimbulkan keterlambatan dalam proyek konstruksi.

Analytical Hierarchy Process (AHP) dikembangkan oleh Thomas L. Saaty pada tahun 1970-an. AHP merupakan sistem pembuat keputusan yang menggunakan model matematis [4]. AHP membantu dalam menentukan prioritas dari beberapa kriteria dengan melakukan analisa perbandingan berpasangan dari masing-masing kriteria. AHP menangani suatu persoalan komplet sesuai dengan interaksi-interaksi pada persoalan itu sendiri. Proses tersebut membuat orang dapat memaparkan sebagaimana kompleksitasnya persoalan itu sendiri dan memperluas definisi dan strukturnya melalui pengulangan. Berdasarkan jurnal "What Is The Appropriate Sample Size To Run Analytic Hierarchy Process In A SurveyBased Research?" yang dilaksanakan pada International Symposium on the Analytic Hierarchy Process. Hasil simulasi menunjukkan bahwa ukuran sampel yang dibutuhkan sesuai dengan bobot kriteria dalam Analytic Hierarchy Process yang diharapkan sebanyak 19 sampai dengan 400 responden.

Expert Choice adalah sebuah perangkat lunak khusus digunakan pada metode AHP, software ini dapat mendukung keputusan yang kompleks dengan membuat keputusan yang lebih efisien, analitis, dan dapat dibenarkan. Data hasil penelitian ini dinalisa menggunakan software exper choice. Hasil perbandingan dalam expert choice ini akan berupa nilai bobot untuk tiap-tiap kriteria dan sub kriteria yang dibandingkan $\mathrm{t}$ choice dalam bentuk matriks perbandingan berpasangan,

\section{Metode}

Penelitian ini dilakukan dengan 3 tahap, tahap pertama dilakukan adalah studi pustaka dan survei awal, tahap kedua dengan pengumpulan data kemudian tahap terakhir dilakukan adalah analisis data dan kesimpulan. Penelitian dilakukan pada beberapa proyek pembangunan basement di daerah DKI Jakarta pada tanggal 21 Oktober 2020 sampai dengan tanggal 31 Oktober 2020 yang dilakukan wawancara secara langsung kepada, project manager, engineer, inspector dan supervisor. Jumlah responden yang diambil sebanyak 21 responden memiliki 2 variabel main faktor yaitu pekerjaan ulang (rework) dan keterlambatan proyek, kemudian $17 \mathrm{sub}$ faktor (12 sub faktor dari pekerjaan ulang, 5 sub faktor dari keterlambatan proyek). Data yang terkumpul dianalisis menggunakan expert choice untuk menentukan bobot kriteria dan alternatif. Tahapan menggunakan AHP dan EC yaitu 
model hierarki, perbandingan berpasangan kriteria dan alternatif, dan analisis sensitivitas [5].

\section{Model Hierarki}

Hierarki adalah alat yang paling mudah untuk memahami masalah yang kompleks di mana masalah tersebut diuraikan ke dalam elemen-elemen yang bersangkutan, menyusun elemen-elemen tersebut secara hierarkis dan akhirnya melakukan penilaian atas elemen-elemen tersebut sekaligus menentukan keputusan mana yang akan diambil. Proses penyusunan elemen-elemen secara hierarki terdiri dari pengelompokan pada elemen-elemen dalam komponen yang sifatnya homogen dan menyusun komponen-komponen tersebut dalam level hierarki yang tepat. Hierarki merupakan sistem yang tingkatan-tingkatan keputusannya bertingkat dengan beberapa elemen keputusan pada setiap tingkatan keputusan. Hierarki dapat dibagi dua jenis yaitu [6]:

- Hierarki struktural, yang berfungsi menguraikan masalah yang kompleks diuraikan menjadi bagian-bagiannya atau elemen-elemennya menurut ciri atau besaran tertentu seperti jumlah, bentuk, ukuran, atau warna,

- Hierarki fungsional, menguraikan masalah yang kompleks menjadi bagian yang sesuai hubungan esensialnya.

Penyusunan hierarki dilakukan agar menggambarkan elemen sistem atau alternatif keputusan yang teridentifikasi. Abstraksi susunan hierarki keputusan: level 1: fokus/sasaran utama, level 2: faktor/kriteria, level 3: sub-factor, level 4: obyektif, level 5: alternatif. Setiap hierarki tidak perlu selalu terdiri dari 5 level, banyaknya level tergantung pada permasalahan yang sedang dihadapi. Tetapi untuk setiap permasahan, level 1 (fokus/sasaran), level 2 (faktor/kriteria), dan level 5 (alternatif) harus selalu ada. Tiap tingkatan dan hierarki keputusan mempengaruhi faktor puncak atau tujuan utama dengan intensitas yang berbeda. Melalui penerapan teori matematika pada hierarki dapat dikembangkan suatu metode yang mengevaluasikan dampak dari suatu tingkat keputusan terdekat diatasnya, berdasarkan komposisi kontribusi relatif (prioritas) dan tiap elemen pada tingkat keputusan terhadap setiap elemen dan tingkat keputusan terdekat. Untuk melihat struktur organisasi 4 Level dapat dilihat pada Gambar 3,

\section{Perbandingan Berpasangan}

Untuk mengukur perbandingan berpasangan bertujuan untuk memberikan nilai tiap kluster agar mengukur kepentingan tiap tingkat dalam hierarki yang terdiri dari 9 skala yang disebut "fundamental scale of saaty [7] dapat dilihat pada Tabel 1.

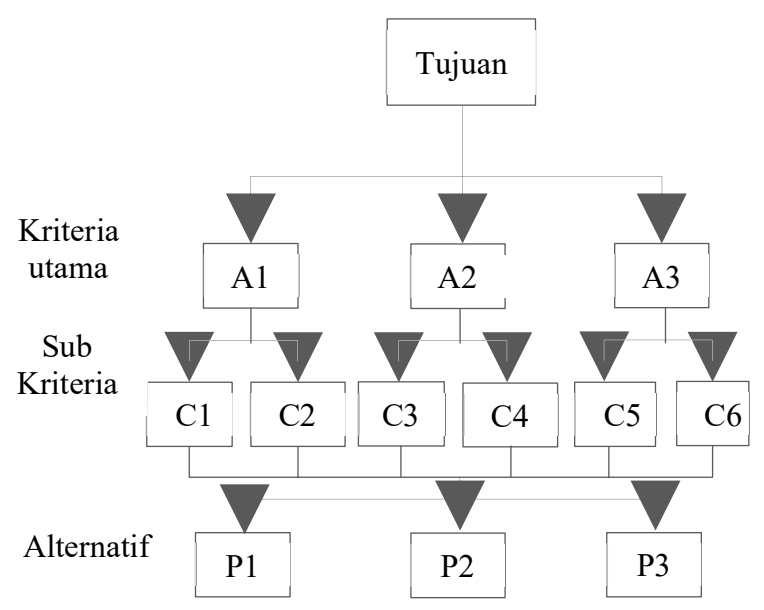

Gambar 3. Lima Model Struktur AHP 4 Level

Tabel 1. Skala Penilaian Perbandingan

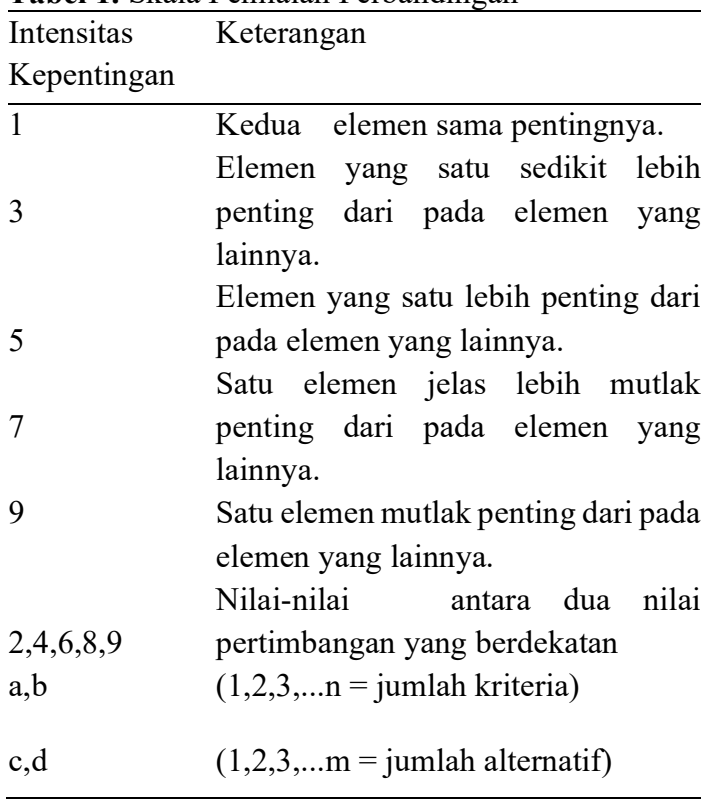

Formulasi matematis pada Analytical Hierarchy Process (AHP) dilakukan dengan menggunakan matriks, sehingga dapat membantu dalam melakukan pengambilan keputusan, secara sederhana berikut merupakan langkah - langkah untuk menentukan bobot pada setiap kriteria dalam penentuan alternatif keputusan diantaranya [8]:

Menentukan geometric mean, dengan persamaan 1.

$$
M G=n \sqrt{\sum_{\mathrm{i}=1}^{\mathrm{n}} \mathrm{Xi}}
$$

dimana:

$M G=$ Geometric Mean

$X i=$ alternatif ke-i 
$n \quad=$ Jumlah data

Melakukan proses normalisasi dengan proporsi geometric mean dengan persamaan 2 .

$$
P i=\frac{M G i}{\sum_{i=1}^{n} M G i}
$$

dimana:

$P i \quad=$ Proporsi alternatif ke-i

$M G i=$ Geometric Mean data Ke-i

$n \quad=$ Jumlah data

Menentukan bobot nilai alternatif terhadap kriteria dengan persamaan 3 .

$$
V i=\sum_{i=1}^{n} P i x W i
$$

dimana:

$P i=$ Proporsi alternatif ke-i

$V i=$ Bobot nilai alternatif ke-i

$W i=$ Bobot kriteria ke-i

Kenyataan, preferensi seorang sering mengalami ketidakkonsistenan, hal tersebut menyebabkan hubungan pada matriks berpasangan menyimpang dari keadaan yang seebenarnya, sehingga matriks tersebut tidak konsisten sempurna. Penyimpangan tersebut diilustrasikan dengan apabila dalam suatu matriks A terdapat penyimpangan kecil pada elemen, maka hal tersebut akan menentukan nilai. Penyimpangan tersebut dinyatakan dengan Consistency Index (CI) pada persamaan 4.

$$
V i=\sum_{i=1}^{n} P i x W i
$$

dimana:

$\mathrm{n}=$ ukuran matriks

Untuk mengetahui konsistensi penilaian yang dilakukan oleh pihak manajeman, maka perlu diakukan perhitungan Consistency Ratio (CR)

Formulasi yang digunakan adalah persamaan 5 .

$$
\begin{gathered}
C R=\frac{C I}{R I} \\
\text { dimana : } \\
\mathrm{CI}=\text { Consistency Index } \\
\mathrm{RI}=\text { Ratio Index }
\end{gathered}
$$

Perbandingan numerik didirikan pada tiap hierarki sehingga berbentuk matrik berpasangan, nilai n merupakan kriteria dalam tingkat hirarki tertentu, sedangkan merupakan sejumlah alternatif, nilai $\mathrm{n}$ dan $\mathrm{m}$ dapat dilihat pada Tabel 2.
Semua matrik berpasangan memiliki 2 sifat dasar berupa diagonal utama bernilai 1 yang mana tiap kriteria dibandingkan dengan nilainya sendiri dan materil kebalikan $\left(\mathrm{i}_{\mathrm{aj}} \mathrm{j}=1(\mathrm{i} \mathrm{bj} \mathrm{b}\right.$ $\left.=1 /\left(\mathrm{ibj}_{\mathrm{a}}\right) ; \mathrm{k}_{\mathrm{cl}} \mathrm{l}_{\mathrm{b}}=1 /\left(\mathrm{k}_{\mathrm{d}} \mathrm{l}\right)\right)$.

Secara umum dapat disetujui prioritas kriteria di estimasi dengan menggunakan eigen vector utama w dari matrik [9]. dapat dilihat pada persamaan 6 .

$\mathrm{A}_{\mathrm{w}}=\lambda_{\mathrm{w}} . \mathrm{w}$

Apabila vektor $\mathrm{w}$ dinormalisasikan maka akan menjadi vektor prioritas dengan mengikuti tujuan $\lambda_{\operatorname{maz}}$ adalah eigen value terbesar dari matrik A dan eigenvector w yang sesuai hanya nilai positif.

Konsistensi matrik pertimbangan ditentukan dengan ukuran dinamakan consistency ratio (CR) dapat dilihat persamaan 5. CI merupakan indek konsistensi $=\left(\lambda_{\operatorname{mak}}-\mathrm{n}\right) /(\mathrm{n}-1)$, $\lambda_{\text {mak }}$ adalah dimensi matrik, RI merupakan index acak dapat dilihat pada Tabel 4.

Apabila CR matrik tinggi, maka nilai tersebut tidak konsistensi dan tidak reliable, apabalia rasio konsistensi $<0,10$ dapat diterima. Apabila nilai tinggi, pertimbangan tidak reliable maka harus dimunculkan. Dengan menggunakan prosedur yang sama, prioritas lokal alernatif dengan cara mematuhi setiap kriteria dapat diestemasi. Langkah terakhir prosedur terdiri dari sebuah keatuan dari prioritas lokal elemen tingkat yang berbeda dalam urutan agar meng-hasilkan prioritas final yang alternatif. Data final, dihasilkan dengan penjumlahan semua eigen vector, adalah sebuah vektor yang menyediakan pengukuran dari bagian yang di simulasikan oleh tiap alternatif dalam mencapai tujuan awal.

Sintesis alternatif dilakukan dengan 2 pendekatan yaitu distributive mode dan ideal mode menggunakan normalisasi dengan membagi skor tiap alternatif oleh skor alternatif [10]. Apabila dalam sistem tertutup (misalnya tidak alternatif ditambahkan atau dipindahkan) alternatif pilihan tergan-tung pada alternatif lain maja boleh digunakan distributive mode. Apabila dalam sistem terbuka dan tidak ingin alternatif lain yang akan mempengaruhi hasil maka ideal mode direkomendasikan [11].

Terdapat 2 variabel yang digunakan dalam mengetahui faktor - faktor yang mempengaruhi pekerjaan pondasi bored pile, pile cap dan secant pile pada proyek basement 5 lapis yaitu variabel pekerjaan ulang dan keterlambatan [12] .

Berdasarkan penjelasan, dapat diartikan bahwa penelitian ini merupakan penelitian yang mengetahui faktor - faktor terjadi pekerjaan ulang dan keterlambatan pada pekerjaan bored pile, pile cap dan secant pile basement 5 lapis. Flowchart metode AHP dengan menggunakan expert choice pada Gambar 4. 
Tabel 2. Perbandingan berpasangan kriteria

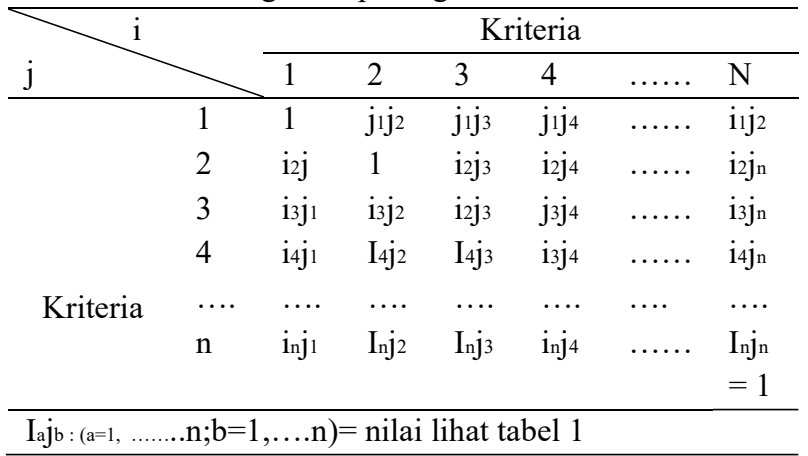

Tabel 3. Perbandingan berpasangan alternatif

\begin{tabular}{|c|c|c|c|c|c|c|c|}
\hline \multicolumn{8}{|c|}{ Kriteria i $(\mathrm{I}=1,2, \ldots \ldots \mathrm{n})$} \\
\hline \multicolumn{2}{|l|}{$\mathrm{K}$} & \multicolumn{6}{|c|}{ Alternatif } \\
\hline 1 & & 1 & 2 & 3 & 4 & $\ldots \ldots$ & $\mathrm{M}$ \\
\hline \multirow{7}{*}{ Kriteria } & 1 & 1 & $\mathrm{k}_{1} \mathrm{l}_{2}$ & $\mathrm{k}_{1} \mathrm{l}_{3}$ & $\mathrm{k}_{1} \mathrm{l}_{4}$ & $\ldots \ldots$ & $\mathrm{k}_{1} \mathrm{l}_{\mathrm{m}}$ \\
\hline & 2 & $\mathrm{k}_{2} \mathrm{l}_{1}$ & 1 & $\mathrm{k}_{2} \mathrm{l}_{3}$ & $1_{2} 1_{4}$ & $\ldots \ldots$ & $\mathrm{k}_{2} \mathrm{l}_{\mathrm{m}}$ \\
\hline & 3 & $\mathrm{k}_{3} \mathrm{l}_{1}$ & $\mathrm{k}_{3} \mathrm{l}_{2}$ & $\mathrm{k}_{2} \mathrm{l}_{3}$ & $\mathrm{k}_{3} 1_{4}$ & $\ldots \ldots$ & $\mathrm{k}_{3} \mathrm{l}_{\mathrm{m}}$ \\
\hline & 4 & $\mathrm{k}_{4} \mathrm{l}_{1}$ & $\mathrm{k}_{4} \mathrm{l}_{2}$ & $\mathrm{k}_{4} \mathrm{l}_{3}$ & $\mathrm{k}_{3} 1_{4}$ & $\ldots \ldots$ & $\mathrm{k}_{4} \mathrm{l}_{\mathrm{m}}$ \\
\hline & $\ldots$ & $\ldots$. & $\ldots$ & $\ldots$ & $\cdots$ & $\ldots$ & $\ldots$ \\
\hline & $\mathrm{n}$ & $\mathrm{Knml}_{1}$ & $\mathrm{kml}_{1}$ & $\mathrm{kml}_{3}$ & $\mathrm{Kml}_{4}$ & $\ldots \ldots$ & $\mathrm{km}_{\mathrm{m}} \mathrm{l}_{\mathrm{n}}$ \\
\hline & & & & & & & $=1$ \\
\hline
\end{tabular}

Tabel 4. Indek acak

\begin{tabular}{lllllllll}
\hline $\mathrm{n}$ & 3 & 4 & 5 & 6 & 7 & 8 & 9 & 10 \\
\hline $\mathrm{R}$ & 0,5 & 0,9 & 1,1 & 1,2 & 1,3 & 1,4 & 1,4 & 1,4 \\
1 & 8 & 0 & 2 & 4 & 2 & 1 & 5 & 9 \\
\hline
\end{tabular}

\section{Tahapan desain penelitian} Informasi umum para pakar

Informasi umum para pakar sangat diperlukan untuk di informasikan pada penelitian ini, karena berpengaruh terhadap hasil penelitian setelah di analisa. Sebelum dilakukan pen-gisian kuisioner kepada responden, setelah hal tersebut dilakukan maka validasi variable harus dilakukan oleh para ahli terlebih dahulu sehingga kuisi-oner tersebut dapat dimengerti oleh responden serta data yang diperoleh sesuai dengan tujuan penelitian yang di inginkan, penulis mengajukan terdapat 5 (lima) orang yang terdiri dari pakar yang mempunyai kompetensi pada penelitian yang dilakukan ini.

\section{Analisis Sensitivitas}

Data yang telah dianalisa dilakukan modifikasi bertujuan untuk mengambil dampak pada hasil tersebut. Analisa sensitivitas terbaik dengan bentuk grafik.

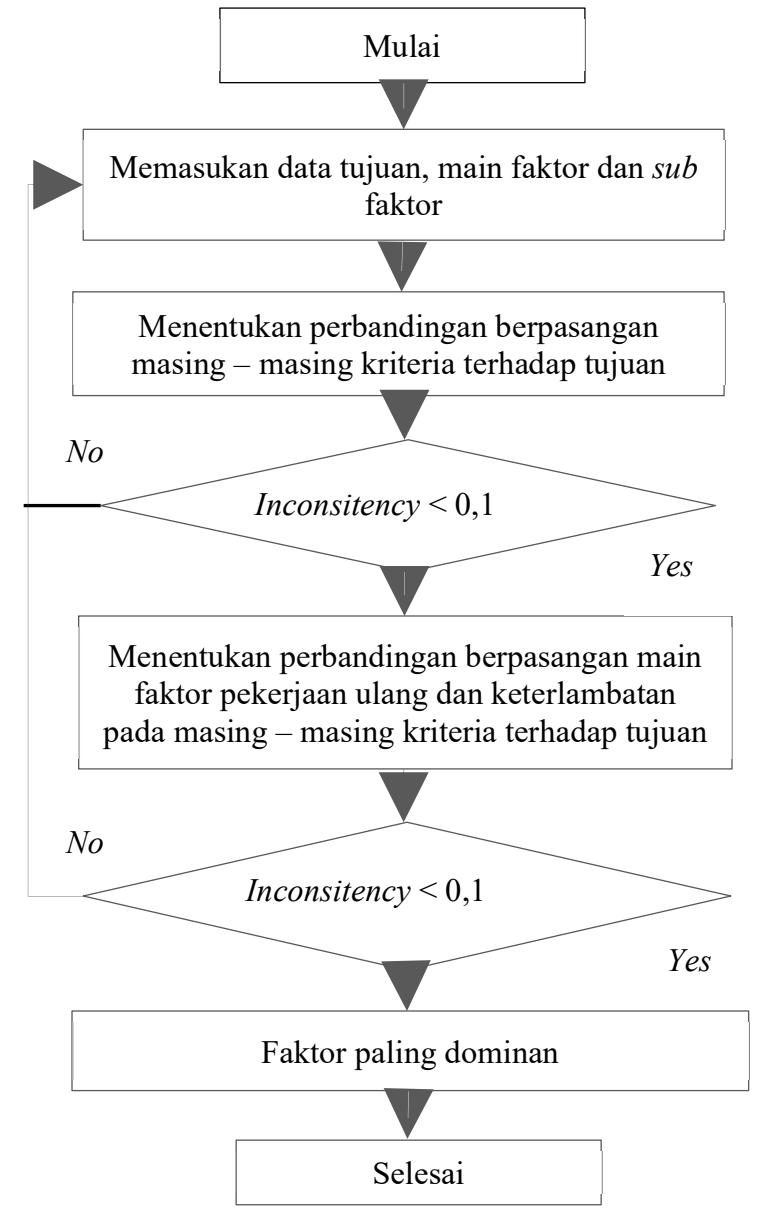

Gambar 4. Bagan Alir Metode AHP Menggunakan Expert Choice

\section{Hasil dan Pembahasan}

\section{Main Faktor}

Agar mendapatkan sub faktor-sub faktor yang sangat berpengaruh, tahapan terlebih dahulu yang dibuat adalah menentukan main faktor, main faktor yang ditentukan berdasarkan kebutuhan serta tujuan penulisan. Penelitian ini menganalisis pekerjaan pondasi bored pile, pile cap serta secant pile pada Tabel. 5

Tabel 5. Skala dan Kriteria Jawaban

\begin{tabular}{ll}
\hline No & Main Faktor \\
\hline 1 & Pekerjaan ulang (Rework) \\
2 & Keterlambatan Proyek \\
\hline
\end{tabular}

Dari 2 main faktor dibagi menjadi $17 s u b$ faktor terdiri dari $12 s u b$ faktor pekerjaan ulang (rework) dan $5 \mathrm{sub}$ faktor dari keterlambatan proyek. Penentuan sub faktor sangat 
diperlukan sebelum melakukan analiss lebih lanjut AHP dengan menggunakan software expert choice, daftar sub faktor yang digunakan dalam menganalisa hubungan variable yang mempengaruhi pekerjaan ulang (rework) pada pekerjaan pondasi bored pile, pile cap dan secant pile basement 5 lapis dapat dilihat pada Tabel 6.

Tabel 6. Faktor - Faktor Mempengaruhi Terjadinya Pekerjaan Ulang gan Keterlambatan

\begin{tabular}{lll}
\hline Main Faktor & Sub Faktor & Kode \\
\hline Pekerjaan ulang & Pengetahuan desain & Y1_1 \\
Pekerjaan ulang & Informasi kontrak & Y1_2 \\
Pekerjaan ulang & Jumlah pekerja kurang & Y1_3 \\
Pekerjaan ulang & Teknologi tidak efektif & Y1_4 \\
Pekerjaan ulang & Manajemen tidak baik & Y1_5 \\
Pekerjaan ulang & Sistem investigasi proyek & Y1_6 \\
Pekerjaan ulang & Komunikasi proyek & Y1_7 \\
Pekerjaan ulang & Prosedur konstruksi & Y1_8 \\
Pekerjaan ulang & Bahan dan peralatan & Y1_9 \\
Pekerjaan ulang & Waktu & Y1_10 \\
Pekerjaan ulang & Sosial dan budaya & Y1_11 \\
Pekerjaan ulang & Keadaan alam & Y1_12 \\
Keterlambatan & Kekurangan bahan & Y2_1 \\
Keterlambatan & Perencanaan & Y2_2 \\
Keterlambatan & Keuangan & Y2_3 \\
Keterlambatan & Karakteristik tempat & Y2_4 \\
Keterlambatan & Sistem Inspeksi & Y2_5
\end{tabular}

Tabel 7. Persentase Tingkat Pendidikan Responden

\begin{tabular}{llc}
\hline No & Pendidikan & Persentase (\%) \\
\hline 1 & Strata 1 & 63 \\
2 & Strata 2 & 27 \\
\hline
\end{tabular}

Tabel 8. Persentase Tingkat Umur Responden

\begin{tabular}{llc}
\hline No & Rentang umur (Tahun) & Persentase (\%) \\
\hline 1 & $20-30$ & 27 \\
\hline 2 & $30-40$ & 37 \\
3 & $40-50$ & 27 \\
4 & $50-60$ & 9 \\
\hline \multicolumn{2}{l}{ Tabel 9. Persentase Jabatan Responden. } \\
\hline No & Rentang umur (Tahun) & Persentase (\%) \\
\hline 1 & Project Manager & 18 \\
2 & Manager & 23 \\
3 & Engineer & 27 \\
4 & Supervisor & 32 \\
\hline
\end{tabular}

\section{Tahap analisa menggunakan Expert Choice}

Pada tahap ini dilakukan melakukan perbandingan dari setiap objective dan sub yang ada dengan menggunakan software expert choice, tahap pertama dilakukan dengan mengetahui penilaian secara komparatif berpasangan, setiap objektif dan sub objektif yang ditentukan dengan mengadakan pembandingan sepasang-sepasang. Yang dimaksud dari kondisi tersebut adalah elemen elemen dibandingkan berpasangan terhadap suatu kriteria yang telah ditentukan yang di implementasikan menggunakan expert choice.

\section{Pembobotan alternatif}

Pada Gambar 5 dan Tabel 11, menjelaskan perbandingan alternatif yang telah dianalisa oleh expert choice pada main faktor pekerjaan ulang (rework)

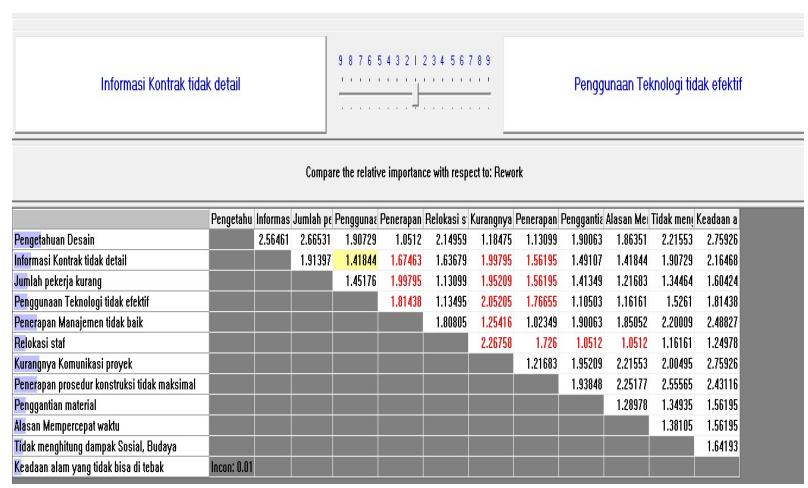

Gambar 5. Gambar Hasil Perbandingan Menggunakan Expert Choice Pekerjaan Ulang (Rework) Combined instance - Synthesis with respect to: Rework
(Goal: Hubungan Variable y > Rework (L: .787)) Overall Inconsistency $=.01$

Pengetahuan Desain

Kurangnya Komunikasi proyek

Penerapan Manajemen tidak baik

Penerapan prosedur konstruksi tidak maksima

Informasi Kontrak tidak detail

Jumlah pekerja kurang

Penggunaan Teknologi tidak efektif

Penggantian material

Alasan Mempercepat waktu

Relokasi staf

Tidak menghitung dampak Sosial. Budaya

Keadaan alam yang tidak bisa di tebak

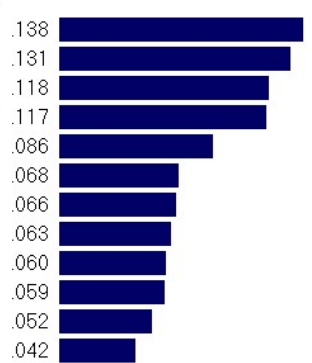

Gambar 6. Gambar Hasil Perbandingan Pekerjaan Ulang (Rework)

Hasil pembobotan alternatif pekerjaan ulang (rework) dapat diterima, dikarenakan oleh nilai inconsitensy kecil dari 0.01. Pada Gambar 5, dan Tabel 10, menjelaskan perbandingan alternatif pada main faktor keterlambatan. 
Tabel 10. Hasil Perbandingan Alternatif Pekerjaan Ulang (Rework)

\begin{tabular}{|c|c|c|c|c|c|c|c|c|c|c|c|c|}
\hline \multirow{2}{*}{$\begin{array}{c}\text { Item } \\
\text { Kegiatan }\end{array}$} & \multicolumn{12}{|c|}{ Hasil Pengelolahan } \\
\hline & $\mathrm{a}$ & $\mathrm{b}$ & $\mathrm{c}$ & $\mathrm{d}$ & e & $\mathrm{f}$ & g & $\mathrm{h}$ & i & $\mathrm{j}$ & $\mathrm{k}$ & 1 \\
\hline $\mathrm{a}$ & & 2,6 & 2,7 & 1,9 & 1 & 2,1 & 1,1 & 1,1 & 1,9 & 1,8 & 2,2 & 2,8 \\
\hline $\mathrm{b}$ & & & 1,9 & 1,4 & 1,7 & 1,6 & 2 & 1,6 & 1,5 & 1,4 & 1,9 & 2,2 \\
\hline $\mathrm{c}$ & & & & 1,5 & 2 & 1,1 & 2 & 1,6 & 1,4 & 1,2 & 1,3 & 1.6 \\
\hline $\mathrm{d}$ & & & & & 1,8 & 1,1 & 2 & 1,8 & 1,1 & 1,2 & 1,5 & 1,8 \\
\hline $\mathrm{e}$ & & & & & & 1,8 & 1,3 & 1 & 1,9 & 1,9 & 2,2 & 2,5 \\
\hline $\mathrm{f}$ & & & & & & & 2,3 & 1,7 & 1,1 & 1 & 1,2 & 1,2 \\
\hline $\mathrm{g}$ & & & & & & & & 1,2 & 1,9 & 2,2 & 2 & 2,8 \\
\hline $\mathrm{h}$ & & & & & & & & & 1,9 & 2,3 & 2,6 & 2,4 \\
\hline $\mathrm{i}$ & & & & & & & & & & 1,9 & 1,3 & 1,6 \\
\hline $\mathrm{j}$ & & & & & & & & & & & 1,4 & 1,6 \\
\hline $\mathrm{k}$ & & & & & & & & & & & & 1,6 \\
\hline 1 & Incon & & & & & & & & & & & \\
\hline
\end{tabular}

Keterangan:

a : Pengetahuan desain

b : Informasi kontrak

c : Pekerja kurang

d : Teknologi tidak efektif

e : Manajemen tidak baik'

f: Investigasi proyek

g: Komunikasi proyek

h: Prosedur konstruksi

i: Penggantian material, peralatan

$\mathrm{j}$ : Mempercepat waktu

$\mathrm{k}$ : Sosial dan budaya

1 : Keadaan alam

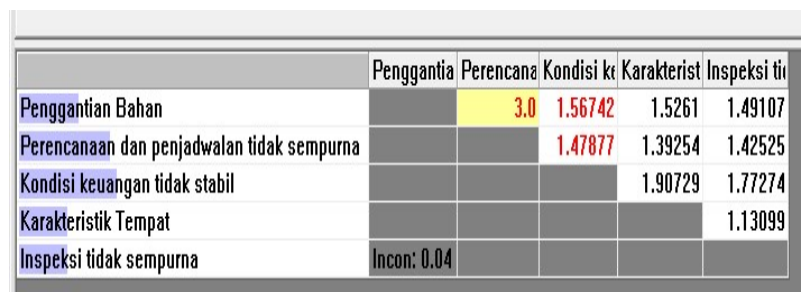

Gambar 7. Gambar Hasil Perbandingan Keterlambatan

Tabel 11. Hasil Perbandingan Alternatif Keterlambatan

\begin{tabular}{|c|c|c|c|c|c|}
\hline \multirow{2}{*}{$\begin{array}{l}\text { Item } \\
\text { Kegiatan }\end{array}$} & \multicolumn{5}{|c|}{ Hasil Kegiatan } \\
\hline & $\mathrm{a}$ & $\mathrm{b}$ & $\mathrm{c}$ & $\mathrm{d}$ & $\mathrm{e}$ \\
\hline $\mathrm{a}$ & & 1,3 & 1,6 & 1,5 & 1,5 \\
\hline b & & & 1,5 & 1,4 & 1,4 \\
\hline $\mathrm{c}$ & & & & 1,9 & 1,7 \\
\hline d & & & & & 1,1 \\
\hline e & & 0042 & & & \\
\hline
\end{tabular}

Keterangan:

a : Bahan

b : Perencanaan dan penjadwalan

c : Keuangan

$\mathrm{d}:$ karakteristik tempat

e : sistem inspeksi

Berdasarkan Gambar 6, dapat dijelaskan nilai prioritas pengetahuan desain 0,138 , komunikasi proyek 0,131 , manajemen tidak baik 0,118 , prosedur konstruksi 0,117 , informasi kontrak 0,86 , jumlah pekerja kurang 0,68 , penggunaan teknologi tidak efektif 0,66 , penggantian material serta peralatan 0,63 , mempercepat waktu 0,06 , investigasi proyek 0,059 , sosial dan budaya 0,052 , keadaan alam 0,042. Di dapat nilai total incosistensy 0,00743 . Nilai prioritas keterlambatan dapat dilihat pada Gambar 8.

Berdasarkan Gambar 6, dijelaskan nilai prioritas keuangan 0,292 , bahan 0,221 , perencanaan dan penjadwalan 0.193 , karakteristik tempat 0,149, dan sistem inspeksi 0,144.

\section{Pembobotan kriteria}

Pada Tabel 12, menjelaskan hasil pembobotan kriteria pekerjaan untuk mengetahui faktor - faktor mempengaruhi analisis pekerjaan pondasi bored pile, pile cap dan secant pile.

\section{Analisis Sensitivitas}

Hasil model sensitivitas ditunjukkan pada Gambar 9, dan gambar hasil dinamik dilihat pada Gambar 10. Gambar sensitivititas grafik dinamik Gambar 9, adalah grafik yang menampilkan hubungan masing masing alternatif dan kriteria. Berdasarkan grafik tersebut menjelaskan faktor yang 
paling berpengaruh terjadi pekerjaan ulang (rework) serta keterlambatan pekerjaan basement 5 lapis adalah pengetahuan desain tim lapangan sebesar 12,2\% dapat dilihat pada Gambar 10.

Combined instance - Synthesis with respect to: Schedule (Goal: Hubungan Variable y > Schedule (L: .213)) Overall Inconsistency $=.00$

Penggantian Bahan

Perencanaan dan penjadwalan tidak sempurna

Kondisi keuangan tidak stabil

Karakteristik Tempat

Inspeksi tidak sempurna

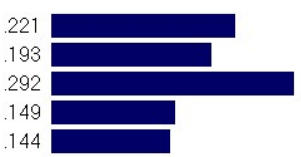

Gambar 8. Gambar Hasil Nilai Prioritas Keterlambatan

Tabel 12. Hasil Perbandingan Kriteria

\begin{tabular}{ll}
\hline Item & Persentase (\%) \\
\hline Rework & 78,7 \\
Keterlambatan & 21,3 \\
Pengetahuan desain tim lapangan & 12,2 \\
Informasi kontrak & 7,6 \\
Jumlah pekerja kurang & 6,1 \\
Penggunaan teknologi tidak efektif & 5,9 \\
Manajemen tidak baik & 10,5 \\
Investigasi proyek & 5,2 \\
Komunikasi proyek & 11,6 \\
Prosedur konstruksi & 10,3 \\
Penggantian material, peralatan & 5,6 \\
Mepercepat waktu & 5,3 \\
Sosial dan Budaya & 4,6 \\
Kedaan alam & 3,7 \\
Bahan & 2,5 \\
Perencanaan dan penjadwalan & 2,2 \\
Keuangan & 3,3 \\
Karakteristik tempat & 1,7 \\
Sistem Inspeksi & 1,6 \\
\hline
\end{tabular}

\section{Simpulan}

Melihat berbagai fungsi basement pada hunian bertingkat tingggi di daerah Provinsi DKI Jakarta, maka perlu dilakukan analisis mendalam mengenai faktor-faktor mempengaruhi terjadinya pekerjaan ulang (rework) serta keterlambatan pada pekerjaan basement 5 lapis, maka dengan melakukan analisis bertujuan mengetahui faktor-faktor terjadinya pekerjaan ulang (rework) serta keterlambatan pekerjaan pondasi bored pile, secant pile dan pile cap proyek basement 5 lapis menggunakan AHP dapat mengetahui kriteria dan alternatif faktor yang paling mempengaruhi dengan soft ware expert choice. Hasil analisis pada penelitian ini menjelaskan bobot kriteria : Pengetahuan desain 12,2\% tim lapangan, Informasi kontrak 7,6 \%, jumlah pekerja kurang $6,1 \%$, penggunaan teknologi tidak efektif $5,9 \%$, manajemen tidak baik 10,59\%, investi-gasi proyek 5,2\%, komunikasi proyek $11,6 \%$, prosedur konstruksi $10,3 \%$, penggantian material peralatan, mempercepat waktu $5,3 \%$, sosial serta budaya 4,6 \%, keadaan alam 3,7\%, bahan 2,5\%, perencanaan penjadwalan 2,2 \%, keuangan 3,3\%, karakteristik tempat $1,7 \%$ dan sistem inspeksi $1,6 \%$.

Berdasarkan analisis, dapat disimpulkan bahwa analisis hubungan variabel yang mempengaruhi rework serta keterlambatan pada pekerjaan pondasi bored pile, pile cap basement 5 lapis terdiri dari 17 Faktor, dengan faktor paling dominan adalah pengetahuan desain tim lapangan sebesar $12,20 \%$ dan faktor yang tidak dominan adalah sistem inspeksi sebesar $1,60 \%$

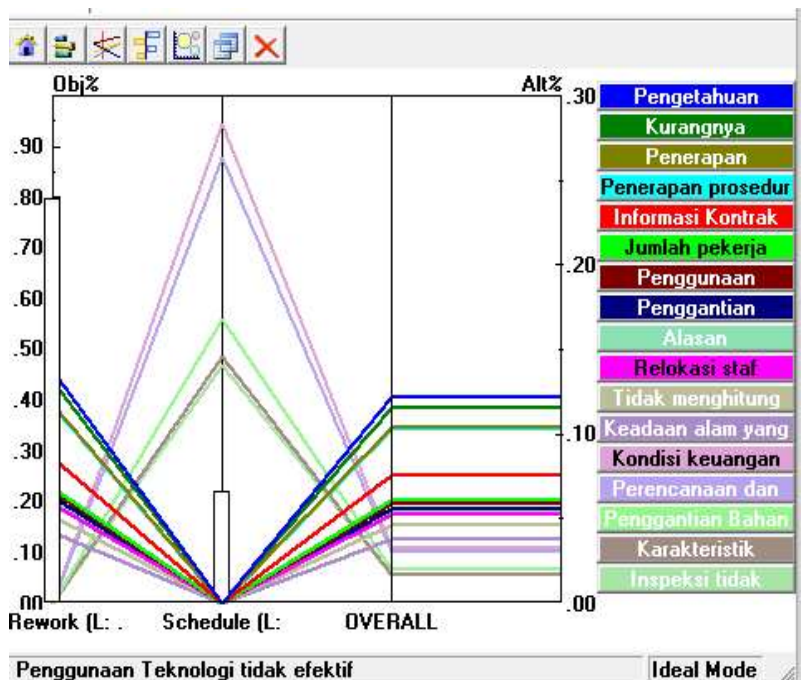

Gambar 9. Gambar Hasil Grafik Dinamik
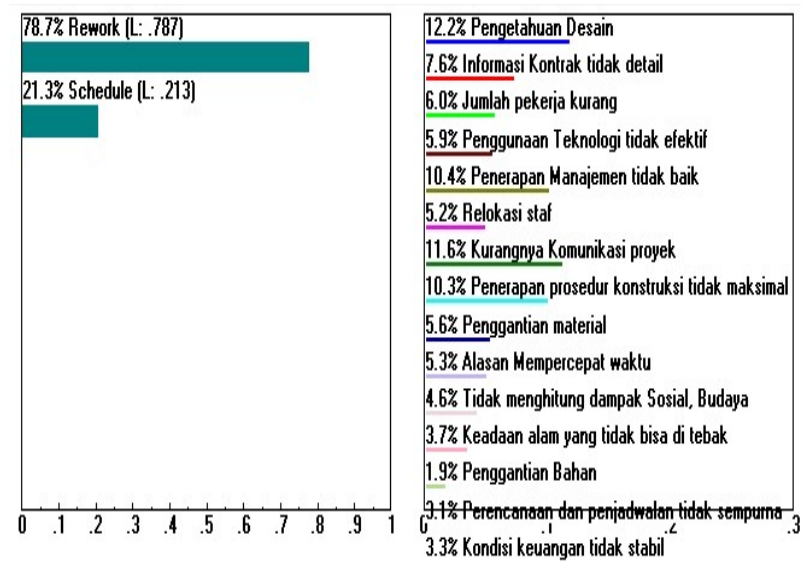

Gambar 10. Gambar Sensitiviti Grafik

\section{Daftar Pustaka}

[1] R. W. M. Wong, "The construction of deep and 
complex basements under extremely difficult urban environment - 3 representing projects in Hong Kong," Adv. Build. Technol., vol. 1, pp. 713-721, 2002, doi: 10.1016/b978-008044100-9/50090-5.

[2] P. E. D. Love, D. J. Edwards, and J. Smith, "Rework Causation: Emergent Theoretical Insights and Implications for Research," J. Constr. Eng. Manag., vol. 142 , no. 6 , p. 04016010 , 2016, doi: 10.1061/ (asce)co.1943-7862.0001114.

[3] A. B. Surya, I. P. A. Wiguna, and E. Suryani, "Pengembangan Model Penyebab Rework Pada Pekerjaan Konstruksi Infrastruktur Jalan Dengan Pendekatan Sistem Dinamik," J. Apl. Tek. Sipil, vol. 15, no. 2, p. 45, 2017, doi: 10.12962/j2579-891x. v15i2.2471.

[4] F. Jalaei and A. Jrade, "Construction Research Congress 2014 CASCE 2014 140," Constr. Res. Congr. 2014, no. 2008, pp. 140-149, 2014.

[5] P. Adamović, Č. Dunović, and M.-M. Nahod, "Expert Choice Model for Choosing Appropriate Trenchless Method for Pipe Laying," 2007, [Online]. Available: https://bib.irb.hr/datoteka/348146.Adamovic_Dunovi c_Nahod_Prag_09_2007.pdf.

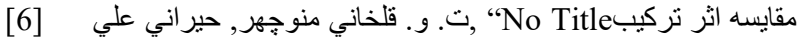

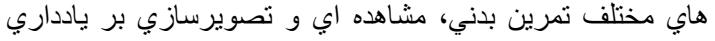

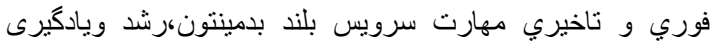

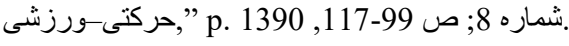

[7] A. E. Husin, T. D. Soehari, Y. S. Prabowo, and Zulfiqar, "Analytical hierarchy process (AHP) implementation in determining document evaluation criteria of post qualification E-tendering knockout phase," Int. J. Eng. Adv. Technol., vol. 8, no. 6, pp. 160-165, 2019, doi: 10.35940/ijeat.E6925.088619.

[8] Nike Shielda Elmania, "Evaluasi dan perbaikan kualitas layanan bri unair pada nasabah (mahasiswa unair) menggunakan analytical hierarchy process (ahp) dan quality function deployment (qfd)," $J$. Manaj., 2016.

[9] T. L. Saaty, "A scaling method for priorities in hierarchical structures," J. Math. Psychol., vol. 15, no. 3, pp. 234-281, 1977, doi: 10.1016/00222496(77)90033-5.

[10] A. Ishizaka and A. Labib, "Analytic Hierarchy Process and Expert Choice: Benefits and limitations," OR Insight, vol. 22, no. 4, pp. 201-220, 2009, doi: 10.1057/ori.2009.10.

[11] I. Millet and T. L. Saaty, "On the relativity of relative measures - accommodating both rank preservation and rank reversals in the AHP," Eur. J. Oper. Res., vol. 121, no. 1, pp. 205-212, 2000, doi: 10.1016/S03772217(99)00040-5.

[12] A. I. Nurani, A. T. Pramudyaningrum, S. R. Fadhila, S. Sangadji, and W. Hartono, "Analytical Hierarchy Process (AHP), Fuzzy AHP, and TOPSIS for Determining Bridge Maintenance Priority Scale in Banjarsari, Surakarta,” Int. J. Sci. Appl. Sci. Conf. Ser., vol. 2, no. 1, p. 60, 2017, doi: 10.20961/ijsascs. v2i1. 16680 . 
Halaman ini sengaja dikosongkan 